This item was submitted to Loughborough's Research Repository by the author.

Items in Figshare are protected by copyright, with all rights reserved, unless otherwise indicated.

\title{
DC Nano-grids: a low cost PV based solution for livelihood enhancement in rural Bangladesh
}

\section{PLEASE CITE THE PUBLISHED VERSION}

https://opus4.kobv.de/opus4-tuberlin/frontdoor/index/index/docld/5185

\section{PUBLISHER}

Universitätsverlag der TU Berlin

\section{VERSION}

VoR (Version of Record)

\section{PUBLISHER STATEMENT}

This work is made available according to the conditions of the Creative Commons Attribution 3.0 Unported (CC BY 3.0) licence. Full details of this licence are available at: http://creativecommons.org/licenses/by/3.0/

\section{LICENCE}

CC BY 3.0

\section{REPOSITORY RECORD}

Khan, M. Rezwan, and Edward D. Brown. 2019. "DC Nano-grids: A Low Cost PV Based Solution for Livelihood Enhancement in Rural Bangladesh". figshare. https://hdl.handle.net/2134/19334. 


\section{INNOVATING ENERGY ACCESS FOR REMOTE AREAS: DISCOVERING UNTAPPED RESOURCES}

Proceedings

of the International Conference

University of California, Berkeley April, 10th to 12th, 2014

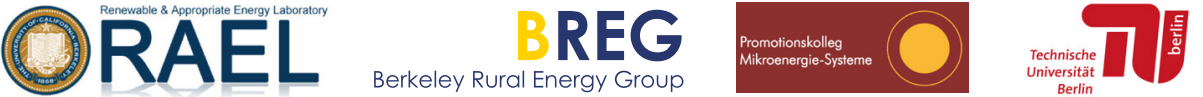

$$
\begin{array}{ll}
\text { micro } & \text { Hans Böckler } \\
\text { Stiftung }
\end{array}
$$

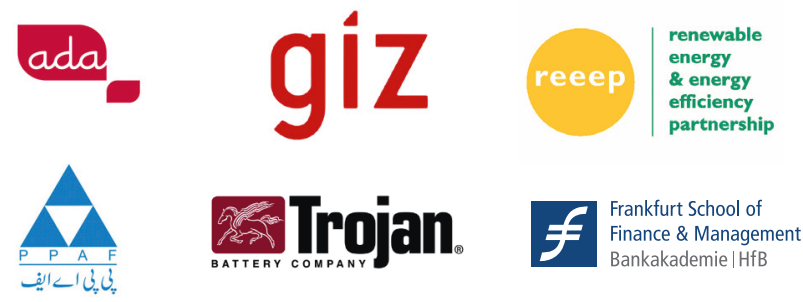



Martina Schäfer | Daniel Kammen | Noara Kebir | Daniel Philipp (editors)

Innovating Energy Access for Remote Areas:

Discovering Untapped Resources

Proceedings 


\section{Scientific Committee}

\section{Chair:}

Prof. Dr. Daniel Kammen, University of California, Berkeley, USA

Prof. Dr. Dr. Martina Schäfer, Technische Universität Berlin, Germany

\section{Sub-Chair for focus area Financing:}

Frankfurt School-UNEP Collaborating

Center for Climate \& Sustainability

\section{(A) $5=\begin{aligned} & \text { Frankfurt School } \\ & \text { UNEP Collaborating Centre }\end{aligned}$}

Energy Finance

\section{Committee:}

Prof. Dr. Lucienne Blessing, Université du Luxembourg

Prof. Dr. Robert Brecha, University of Dayton, USA

Laura Foschi, ADA, Luxembourg

Prof. Marek Hudon, Solvay Brussels School of Economics and Management, Belgium

Dr. Michael Jakob, Mercator Research Institute on Global Commons and Climate Change,

Germany

Noara Kebir, MicroEnergy International, Germany

Marlis Kees, GIZ, Germany

Prof. Dr. M. Rezwan Khan, United International University, Bangladesh

Prof. Dr. Johann Köppel, Technische Universität Berlin, Germany

Prof. Dr. Stefan Krauter, University of Paderborn, Germany

Prof. Dr. Walter Leal, HAW Hamburg, Germany

Prof. Dr. Inmaculada Martinez-Zarzoso, University of Goettingen, Germany

Ellen Morris, Ph.D., Columbia University, USA

Bruce Nordman, Lawrence Berkeley National Laboratory, USA

Shonali Pachauri, Ph.D., IIASA, Austria

Debajit Palit, TERI, India

Daniel Philipp, MicroEnergy International, Germany

Prof. Dr. Gisela Prasad, University of Cape Town, South Africa

Kilian Reiche, iiDevelopment, Germany

Christa Roth, FOODandFUEL, Germany

Dana Rysankova, World Bank, USA

Prof. Dr. Tomohiko Sakao, Linköping University, Sweden

Dr. Jan Steckel, Mercator Research Institute on Global Commons and Climate Change, Germany

Dr. Tania Urmee, Murdoch University, Australia

Prof. Bruce Usher, Columbia Business School, USA

Steven R. Wilson, Georgetown University, USA 


\section{Innovating Energy Access for Remote Areas: Discovering Untapped Resources}

Proceedings of the International Conference April 10th to 12th, 2014

University of Berkeley

Editors: Martina Schäfer Daniel Kammen Noara Kebir

Daniel Philipp 
Bibliographic information published by the Deutsche Nationalbibliothek

The Deutsche Nationalbibliothek lists this publication in the Deutsche Nationalbibliografie; detailed bibliographic data are available in the Internet at http://dnb.dnb.de/

Universitätsverlag der TU Berlin, 2014

http://www.univerlag.tu-berlin.de

Fasanenstr. 88, 10623 Berlin

Tel.: +49 (0)30314 76131 / Fax: -76133

E-Mail: publikationen@ub.tu-berlin.de

This document is licensed under the Creative Commons

Attribution 3.0 DE License (CC-BY 3.0 DE): http://creativecommons.org/licenses/by/3.0/de/

Printing: docupoint $\mathrm{GmbH}$

ISBN 978-3-7983-2693-4 (print)

ISBN 978-3-7983-2694-1 (online)

Published online on the Digital Repository of the Technische Universität Berlin:

URN urn:nbn:de:kobv:83-opus4-51851

http://nbn-resolving.de/urn:nbn:de:kobv:83-opus4-51851 


\title{
DC Nanogrids: A Low Cost PV Based Solution for Livelihood Enhancement for Rural Bangladesh
}

\author{
M. Rezwan Khan \\ United International University \\ Dhaka, Bangladesh \\ Email: rezwanm@uiu.ac.bd \\ Edward D. Brown \\ Loughborough University \\ Loughborough, UK \\ Email: E.D.Brown@1boro.ac.uk
}

\begin{abstract}
A concept paper, along with cost estimations, is presented proposing the development of very small sized solar PV grids, which we have termed nano-grids. These grids allow the incorporation of developmental activities such as irrigation, along with household usage of electricity. It is argued that the developmental activity should be chosen in such a way that it matches with the seasonal variation in insolation and load demand to keep the energy cost to a minimum.
\end{abstract}

Keywords Nano-grid; DC-grid; livelihood enhancement; irrigation; household load in Bangladesh.

\section{Introduction}

Falling PV prices in the world market have opened up wide opportunities for accelerated deployment of solar energy technologies in developing countries like Bangladesh. Although, the energy cost of a PV based system is still higher than that of grid power, there is ample scope for PV based energy generation for offgrid regions where the potential for grid extension is likely to remain low. Studies of off grid rural areas in Bangladesh (Khan, et.al, 2012) indicate that the main fuel for lighting in the off-grid areas are kerosene based lamps (Kupi or Harricane) and a family on average spend Tk. 200 per month on the cost of the kerosene. Besides the high cost of this imported oil to families on low incomes, these lamps produce significant fumes posing health threats and are prone to fire hazards. The significant growth of the Solar Home System (SHS) in Bangladesh (www.idcol.org) started to take place at a time when the cost of solar PV panels was about two times higher than its present price. Although the energy cost of the SHS was very high at that time in comparison to grid electricity, the actual cost for lighting a house with efficient fluorescent lamps via the SHS were comparable to the expenditure that families had been making on kerosene purchases, with the advantage that the health hazards from the fumes and the fire hazard from the open flames had effectively been eliminated. Additionally, people had the opportunity to charge mobile phones and watch $\mathrm{TV}$ in the case of the installation of systems with panel sizes of higher than 50Wp (www.idcol.org) which constituted another very important incentive for families to opt for a SHS. As the price of the PV started to fall, the rate of penetration of SHS in the market soared accordingly. Today, more than 50,000 SHS are being installed every month in Bangladesh (www.idcol.org) and it is considered as one of the fastest growing and most successful solar programs in the world.

Nevertheless, for all of the successes of the Bangladesh SHS programme, it is clear that for a sizeable proportion of the rural population the costs of such systems remain beyond them. In this context, the kinds of solar lighting products which have been promoted via the Lighting Africa initiative (www.lightingafrica.org) have been proposed as a very low cost solution for these types of households. Typically, these types of solutions have involved the use of very small PV panels, sometimes termed Pico-PV. The typical size of the PV panels vary from $5-10 \mathrm{~W}$, with a small storage battery and $2 / 3$ LED lights. As these systems are very small, the typical cost is low and the system is well within the affordable range of the population remaining at the bottom of the pyramid (BOP) in Bangladesh. There are currently several propositions from a variety of international organizations and funders to implement similar systems in rural Bangladesh to promote these types of solutions to the lighting needs of the poorest Bangladeshi communities However, before taking a hasty decision to roll out similar programmes in Bangladesh based on the success story of Lighting Africa, it is important to analyze socioeconomic conditions in rural Bangladesh. One of the most striking dissimilarities between communities in rural Bangladesh and most parts of rural Africa is the much higher population density in the former which leads to people living closely in houses clustered in a small area. This may offer possibilities for pursuing an alternative solution in Bangladesh. A simple observation will show that the electricity generated by smaller PV panels is more expensive than that generated by larger panels (as, for example, a $100 \mathrm{Wp}$ panel is less than 10 times more expensive than a $10 \mathrm{Wp}$ panel) as there are some fixed overhead costs like framing and the connectors at the back of the panel. Very small systems also require small sized batteries and small sized lead-acid batteries are usually not very good quality meaning that the practical options left are Nickel or Lithium based batteries. These Nickel or Lithium based batteries are 45 times more expensive than an equivalent lead-acid battery which also adds to the relative cost of small systems. It is estimated (Khan et.al., 2012) that the energy cost of a small system with this type of more ex- 
pensive battery is almost two times that for a conventional lead-acid battery based energy storage system.

So there are significant questions over whether smallscale pico-PV solutions are likely to be the most appropriate for the Bangladesh context, particularly when one considers the growing identification of the limitations of the SHS even amongst those households where it is more or less affordable. Despite all the positive features of the SHS, it has a very serious limitation in terms of its potential to directly affect an individual household's ability to improve its income generation and overall quality of life (Blunck, M., 2007; Mondal, and Klein, 2011, p.17).The energy output of a SHS is so small that it can only support the meeting of basic lighting necessities and perhaps the charging of mobile phones and the running of a TV as a basic entertainment for rural people. Studies (Khan et.al., 2012) made on energy needs in rural Bangladesh, however, indicate that there is demand for further very important facilities. One of these is a fan for comfort during the hot summer months and the others include income generating activities like irrigation, saw mill, flourmill for rice or wheat crushing, rice husking machine etc. Irrigation in particular seems to be a very good prospect as $2 / 3$ rd of the total number of irrigation pumps driven by diesel in the country are located in off-grid areas. Demand of refrigerator is still very limited due to economic limitations of the households.

In this paper we propose a community based small sized centralized solar PV system, termed 'nano-grid' for its small size (in contrast to the larger networks envisaged under terms such as mini-grids), that can provide energy to 15-20 households and can support small scale developmental activities like irrigation. The energy cost is quite competitive and the capital cost is low as the system is quite small.

\section{Solar PV based Irrigation in Bangladesh}

Irrigation is one of the major energy-demanding activities carried out in rural Bangladesh as Bangladesh is predominantly an agricultural country. Bangladesh has a monsoon climate where there is plenty of rainfall during the months from June to September. Indeed, sometimes there is too much rainfall and flooding takes place. The main cropping seasons are 'Aman' harvested during the month of November and 'Robi' harvested during the month of May. The 'Robi' season is predictably dry with plenty of sunshine and with proper irrigation this is the most important crop producing season for Bangladesh. However more than $60 \%$ of the rural area is not connected to the national electricity grid and irrigation mainly depends on diesel-based engines in these areas. The cost of diesel in the city areas is about Tk. 61 per litre and it is at least $20 \%$ higher in the rural areas due to the incidence of transportation and storage costs. Bangladesh imports USD 1bn worth of diesel for use in the agricultural sector alone

(http://www.nationmaster.com/).

The cost of diesel-based irrigation at the field level is Tk. 21 per kW-hr equivalent of electricity. The irriga- tion pump owners charge about $25 \%$ of the value of the crop produced for irrigating the land for a season.

With this background scenario, our studies presented here, indicate that with the present price of PV panels and prevailing patterns of solar radiance, solar PV based irrigation can be cheaper than diesel based irrigation in Bangladesh. However, it is important to understand that irrigation requirements in any particular season varies with the rain fall, the crops grown etc. and any dedicated irrigation scheme will not be cost effective as the PV energy will be wasted during the non irrigating months (from June to September). So, for any PV-based alternative to diesel-based irrigation to be viable, it will be very important to integrate the irrigation scheme along with a rural grid so that PV energy will have alternative usage. Another very important aspect is the monthly sunshine availability. During the main irrigating months (February to May) the temperature is relatively low and household demand for electricity is therefore also lower as, for example, cooling fans are likely to be one of the main sources of energy demand. So, we would expect that the higher sunshine during the irrigating months can very effectively be utilized for irrigation without causing shortages for household energy consumption. On the other hand, during the months of June to September, there is plenty of rainfall and the sunshine is relatively low resulting in less production of PV energy. This, however, is the season when irrigation needs are minimal and the PV output can be very effectively used for household purposes. So, our assumption is that if we consider the distribution of sunshine and the seasonal variation of demand including for irrigation, net electricity requirement would appear to match the availability of PV output. This has the added benefit of suggesting very effective usage of the PV output, leaving the likely amount of unutilized energy at a minimum.

Although the proposed nano-grid uses battery backup for supply of energy during the night hours, irrigation can be done during the day time without battery backup that reduces the cost of electricity for irrigation can make the scheme commercially viable. It is worth mentioning that the requirement of battery backup increases the cost of PV energy by more than $70 \%$.

\section{The Concept of DC nanogrid: Its Feasibility in the Context of Bangladesh}

Drawing together the discussion in the previous sections, it can be seen that the nano-grid idea is based on the fundamental concept of the Solar Home System, where the basic necessities of households are met, but at the same time some small scale applications like irrigation can also be incorporated. This concept takes advantage of the fact that houses in Bangladesh are usually clustered together in rural areas in a group of 15-20 houses (within a diameter of less than $150 \mathrm{~m}$ ). A schematic diagram depicting the concept is shown in Fig. 1. In the proposed nano-grid system, something like a 1.5 to $2 \mathrm{kWp}$ PV system is installed in a small cluster of households within a radius of $60-70 \mathrm{~m}$ and power is distributed to $10-15$ households from this system. The PV panels and the battery used in the proposed nano- 
grid will be connected in series in such a way that the grid voltage is $220 \mathrm{~V}$ DC (nominal) and the households are supplied with this voltage. There are already strong voices being raised regarding the advantages of DC grids (Khan, 2012).

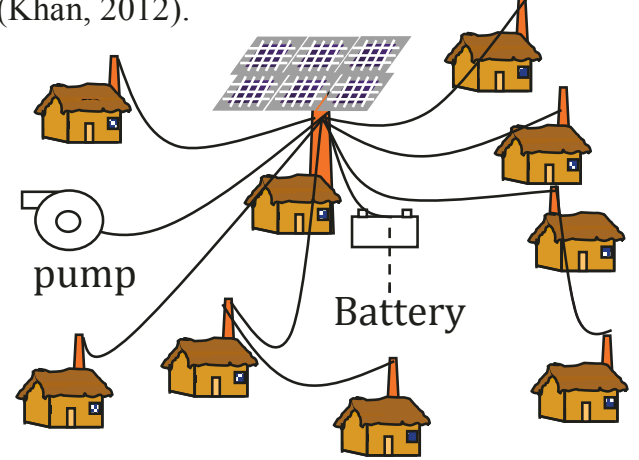

Figure 1: Schematic diagram for the nano-grid. Roof top locations of one or two houses will be chosen for PV installation and the storage battery will be placed in a convenient location close to it.

As described in the later part of this section, the main household loads for this system are likely to be lighting, TV, fan and mobile phone. The LED or CFL lamps and TV have their own built in controller circuits that make them insensitive to DC or AC supply. These days, brushless DC fans are widely available in the market. Although the brushless DC fans are more expensive, they are much more efficient $(\sim 80 \%)$ than the usual induction motor based AC fans (efficiency $\sim 60 \%$ ). The higher cost of the brushless DC fans is likely to be compensated within three years considering the lower power consumption of the fans. However, in case of irrigation pumps or some other income generating activities a separate inverter is likely to be needed. The advantage of the DC grid is its low cost, as no inverter is needed and at the same time this avoids inverter energy losses. Our preliminary estimates indicate that there can be more than a $25 \%$ cost saving by avoiding inverters in the grid.

Considering the typical load in a household, the expected summer time (May to September) load is around 3 times the expected winter (November to March) household loads. This, as explained above, is due to the fact that there is expected to be high usage of fans in summer due to hot weather condition. The average typical household load in rural Bangladesh given below in Table I and Table II. The demand for refrigerator is not considered at this stage as it goes beyond the affordability of the average households.

From Table I and Table II it can be clearly seen that fans constitute a significant part of the household load in summer whilst the zero fan load in the winter months reduces the total load to less than half. Although the mobile charger is an important component, its actual energy consumption is very small and has not been included in the tables. The surplus generated from the significant fall in the household demand is proposed to be used for developmental activities like irrigation during the dry months.

Fig. 2 shows the average daily solar radiation on a horizontal flat surface in Bangladesh. The main irrigation season is from February to $1^{\text {st }}$ week of May and the weather remains reasonably dry and cool until the end of April.

Table 1:House hold consumption (summer months)

\begin{tabular}{|c|c|c|c|}
\hline & Light & Fan & TV \\
\hline \%House hold (HH) & 100 & 100 & 25 \\
\hline No./HH & 3 & 2 & 1 \\
\hline Watt/unit & 5 & 20 & 30 \\
\hline Hrs of usage, hr & 4.5 & 8 & 8 \\
\hline Diversity & 0.8 & 0.8 & 0.8 \\
\hline Energy/day, W-hr & 54 & 256 & 48 \\
\hline \multicolumn{3}{|c|}{ Total/day, W-hr } & 358 \\
\hline \multicolumn{3}{|c|}{ Avg.load/HH, Watt } & 62.5 \\
\hline
\end{tabular}

Table 2: House hold consumption (winter months)

\begin{tabular}{|c|c|c|c|}
\hline & Light & Fan & TV \\
\hline \%House hold (HH) & 100 & 100 & 25 \\
\hline No./HH & 3 & 2 & 1 \\
\hline Watt/unit & 5 & 20 & 30 \\
\hline Hrs of usage & 6.0 & 0 & 10 \\
\hline Diversity & 0.8 & 0.8 & 0.8 \\
\hline Energy/day, W-hr & 72 & 0 & 60 \\
\hline \multicolumn{2}{|c|}{ Total/day, W-hr } & 132 \\
\hline Avg.load/HH, Watt & 22.5 \\
\hline
\end{tabular}

It is interesting to note that sunshine is higher during these months, which together with relatively low demand for fan-use in the house holds during this period generates sufficient surplus energy to divert it for irrigation. Our preliminary calculations show that a small pump of $1.1 \mathrm{~kW}(1.5 \mathrm{HP})$ can be easily run to irrigate the fields. During the months after June, the rainy season starts and demand for irrigation is reduced to around 5$10 \%$.

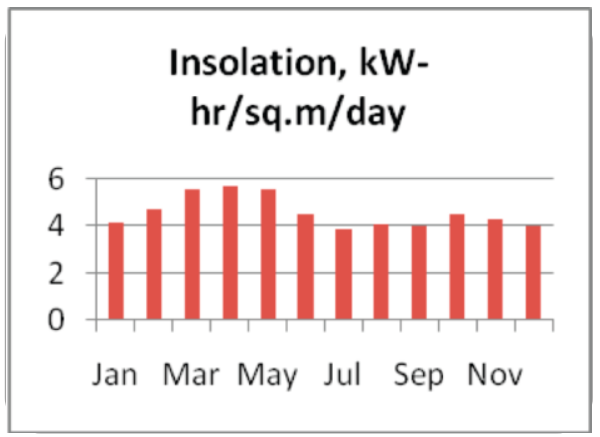

Figure 2: Month wise average daily insolationin Bangladesh.

Although the sunshine is lower during the rainy season (June-September), absence of irrigation makes the overall energy demand lower and a well-designed system should be able to cope quite satisfactorily with household demand. For a very small system, we esti- 
mate that a $1.1 \mathrm{~kW}$ pump and 10 households can be supplied with the necessary primary energy needs using a $1.9 \mathrm{kWp}$ PV system with a $500 \mathrm{AH}, 12 \mathrm{~V}$ battery as storage. During the daytime it is recommended that the pump will run from $10.00 \mathrm{am}$ to $2.30 \mathrm{pm}$. The rest of the time will be dedicated to battery charging. At the same time, the panel size is such that it can generate enough energy even in rainy, cloudy or foggy days to keep the battery size small compared to those used in SHS. Fig.3 below gives a month wise energy demand and production scenario for such a system.

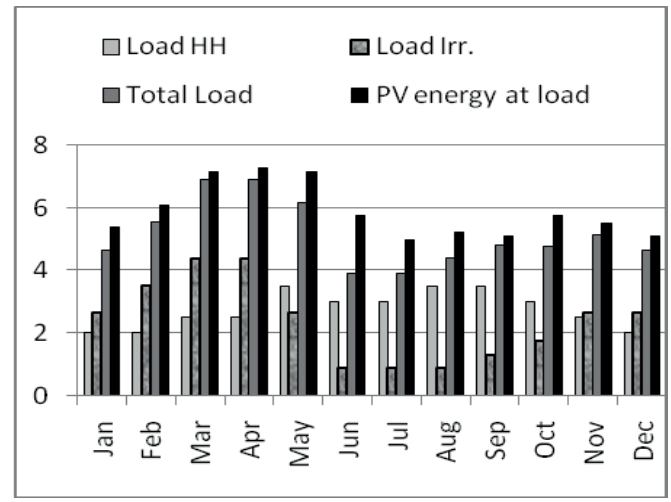

Figure 3: Month wise average daily energy (kW-hr) budget for a $1.9 \mathrm{kWp}$ PV nano-grid supplying power to

10 households and an irrigation pump of $1.1 \mathrm{~kW}$

\section{A Calculation for water Delivery for a Small Irrigation Pump}

A $1.1 \mathrm{~kW}(\sim 1.5 \mathrm{HP})$ irrigation pump can run quite satisfactorily if the input power is within $1000-800 \mathrm{~W}$. A $1.1 \mathrm{~kW}$ electric pump driven by an inverter, having an overall efficiency of $50 \%$, can pump around 90,000 litres of water per day ( 4 hours of run time) from an average head of $7 \mathrm{~m}$. In the case of a submersible deep tube well the figure will be significantly lower due to the higher water head. Most of the irrigation pumps in Bangladesh use shallow tube wells not exceeding a depth of 6-7m.Rice is the most important crop in Bangladesh that needs irrigation during the dry months, 90,000 litres per day can irrigate about 6-7 acres of rice field for a whole season ( 3 months). In the case of other crops like vegetables, wheat or maize the area of irrigated land will bemuch larger as they require much less water than rice cultivation.

\section{The Cost Calculation for the Proposed nano-grid}

\section{Cost of the system and electricity}

The description of a model system is given below

Size of the PV $-1.9 \mathrm{kWp}$

Size of the battery bank $-480 \mathrm{AH}$ at $12 \mathrm{~V}$

One irrigation pump (AC) $-1.1 \mathrm{~kW}(1.5 \mathrm{HP})$

No. of households -10

Summer load per house hold - 360W-hr per day

Winter load per house hold - $135 \mathrm{~W}$-hr per day

Estimated total cost of the system including installation and accessories is USD 4652. Based on IDCOL model of financing ( $50 \%$ grant, $30 \%$ loan at $6 \%$ interest rate for 8 years and 20\% equity) energy cost for household electricity is USD $0.35 / \mathrm{kW}$-hr and energy cost for irrigation is USD $0.20 / \mathrm{kW}-\mathrm{hr}$.

Considering a monthly connection charge of USD 1.25 electricity bill for an average household for summer months is USD 5.0 and that for winter months is USD 2.7.Corresponding irrigation energy cost per season is $10.7 \%$ of the crop produced for rice fields. As mentioned earlier, the usual charge for diesel based irrigation is $20-25 \%$ of the crop produced in the irrigated fields. It is worth mentioning here that the average energy cost in a SHS under a similar financing model is close to Tk. 40. As SHS has only fixed load of light, mobile charger and/or TV, it cannot accommodate the seasonal variation of sunshine resulting in underutilization of the available PV energy. The nanogrid provides energy at a lower cost with more options for household gadgets. Apart from household use, it can incorporate a small sized irrigation pump that can have significant impact on agriculture.

\section{Conclusions}

The paper has proposed the concept of DC nano-grid highlighting its technical advantages and some of the economic and social considerations involved in their development. These are not capital intensive solutions as their size is quite small and can be easily implemented in a small community overcoming the financing difficulties; unlike, for example, the case of large scale mini-grids (Ulsrud et.al, 2011). At the same time, supply of DC voltage instead of AC at the household level avoids the relatively high cost of inverters eliminating inverter losses, particularly when the load demand is less than $10 \%$ of the peak during late night hours. Considering the sunshine and climatic conditions of Bangladesh, irrigation is incorporated with the system to run directly from the PV (without battery) during the dry seasons when the sunshine is high but house hold load demand is low, taking the advantage of energy surplus in the nanogrid. The solar PV irrigation energy cost, as presented in section 4, is lower than diesel based irrigation costs in Bangladesh. 


\section{References}

Blunck, M. (2007) 'Electricity and sustainable development: Impacts of Solar Home Systems in Rural Bangladesh', Diploma Thesis, Department of Geography of Johannes Gutenberg, University ofMainz, Germany, May 2007.

Khan,M. Rezwan, 'A Stand Alone DC Micro-grid for Electricity Supply in Rural Bangladesh', Proceedings of International Conference on the Developments in Renewable Energy Technology, Dhaka, Bangladesh, January 2012.

Khan, M. Rezwan, Khan, M. Fayyaz, Chowdhury, Shahriar Ahmed, 24kW solar-Diesel hybrid power system for off grid Shonatala Island of Nasir Nagar upazilla of Brahminbaria districs, GIZ -UIU study report,2012.

Mondal, A. And Klein, D. (2011) Impacts of solar home systems on social development in rural Bangladesh, Energy for Sustainable Development, 15 (1), pp. 17-20.

Ulsrud, K., Winther, T., Palit, D., Rohracher, H. and Sandgren, H. (2011) The Solar Transitions research on solar minigrids in India, Energy for Sustainabe Development, 15 (3). (minigrid)

Gas Diesel oil consumption in agriculture statistics, http://www.nationmaster.com/graph/ene_gas_oil_con_in_a gr-gas-diesel-oils-consumption-agriculture

IDCOL website: www.idcol.org

Lighting Africa website : www.lightingafrica.org 